\title{
Foams of togetherness in the digital age: Sloterdijk, software sorting and Foursquare
}

\author{
Sarah Widmer and Francisco Klauser \\ Institute of Geography, University of Neuchâtel, Neuchâtel, 2000, Switzerland \\ Correspondence: Sarah Widmer (widmer.sarah@gmail.com)
}

Received: 13 February 2020 - Revised: 1 June 2020 - Accepted: 10 July 2020 - Published: 4 September 2020

\begin{abstract}
The article brings together Peter Sloterdijk's theory of spheres and literatures on the socio-spatial implications of the functioning of software. By examining the growing personalization of search results for recreational places on spatial media like Foursquare, we make the case for Sloterdijk's conceptualization of "foam" offering an interesting contribution to the analysis and critique of contemporary algorithmic life, in particular with regard to the liquidity and fragility of the forms of togetherness in "co-isolation" created by such applications. In emphasizing the impermanence and ambiguities of these fleeting mediations, the article also points to the politics of these algorithmic foams, whose logics of categorization and socio-spatial sorting become increasingly difficult to understand, politically address or challenge.
\end{abstract}

\section{Introduction}

Most social networking applications now also incorporate spatial aspects (Wilken and Goggin, 2015). Examples range from the georeferencing of posts on Twitter or Facebook to location-based social networks (Swarm, Snap Map) or dating apps (Tinder). Inversely, "new spatial media" (Crampton, 2009; Kitchin et al., 2017) such as Foursquare, Yelp or Tripadvisor also integrate social aspects, as they are based on user-generated content; allow various forms of interaction between content producers; and often highlight the activity of specific "others", defined as "travel experts", "people like you", "followees" and so on. Although these media present important differences in form and content, they have in common at least two aspects: first, they work though combinations of the "social" and of the "spatial", in which location mediates social interaction and, in turn, social connections mediate spatial practices; second, they do so through algorithms, that is, in automatic ways.

This article examines one type of such socio-spatial media: local search engines, i.e. applications that indicate sites of interest such as restaurants and cafés. Importantly, as personalization has become a pervasive aspect of digital cultures, many local search engines work not only by combining the spatial and the social but also by producing specific instantiations of the self. As evidenced by the launch of "Your match" on Google Maps Explore in 2018, calculating "how likely you are to enjoy a place based on your own preferences" (Blog Google, 2018); by the introduction of "recommendations tailored to you ... with the help of machine learning" on Yelp (Blog Yelp, 2018); or by the long-established personalization of place recommendations on Foursquare, these media create splintered spatialities based on a calculation of who we are and of what our social affiliations should be. Referring to the example of the smartphone app Foursquare and developing a previous engagement with the problematic (Widmer, 2015), the present article explores what it means to live in these mediated relations to space, alterity and the self.

On a conceptual level, the article combines existing literatures on contemporary "algorithmic life" (Amoore and Piotukh, 2015) with Peter Sloterdijk's magnum opus Spheres (Sloterdijk, 2011, 2014, 2016). As Sloterdijk's theory of spheres addresses the question of coexistence in spatial formations (i.e. spheres), we consider it well-suited to studying how apps such as Foursquare combine "the social", "the spatial" and "the self" to create specific forms of togetherness. We therefore suggest that Sloterdijk's theory and terminology offer an important contribution to the analysis of how algorithms shape the (co)existential spatialities of the everyday. 
More precisely, we dwell on the concept of "foams" - the third type of sphere addressed in the trilogy - which Sloterdijk uses to evoke our contemporary individualistic and post-holistic world. Foams are fragile, flexible and ephemeral spheres, where coexistence unfolds in a paradoxical state of co-isolation (i.e. individual spheres exist in a state of adjacency with each other, being, thus, neither completely isolated nor really connected). We therefore draw on the concepts of foams and co-isolation to address the spheres (both self-centred and dependent on the data produced by others) created by Foursquare's algorithms and their flexible and ephemeral nature. By focusing on how users experience these co-isolated and ephemeral spatialities, our article underlines the ambiguities arising from attempts to inhabit these fleeting realities. By pointing to this, we also aim to address the politics of these algorithmic foams, whose inconsistency and impossibility of being clearly grasped unveil a problematic aspect of the work performed by machine learning algorithms: the growing difficulty in understanding and in politically addressing their logics of categorization and sorting.

\section{Questioning software sorting}

In recent years, a growing interdisciplinary literature has explored how software shapes the spaces of the everyday (Graham, 2005; Kitchin and Dodge, 2011; Thrift and French, 2002). This literature has problematized software as a "grammar of action" (Kitchin and Dodge, 2011:87) that is produced by and, in turn, reproduces specific classifications and orderings of reality and, as such, is intrinsically bound up with space (Klauser, 2017). More specifically, two complementary lines of enquiry have dealt with the socio-spatial implications of software.

For one, a number of scholars have explored the power issues inherent in the way software functions as a tool for socio-spatial sorting (Lyon, 2005; Murakami Wood and Graham, 2006). This work highlights and questions the exclusionary and discriminatory potential inherent in contemporary "governing through code" (Klauser et al., 2014). Geographically speaking, software is approached as a means of automatically demarcating rights to and through space, accessibilities and speeds, thus orchestrating spatial flows and presences in highly adaptable and differentiated, yet often fundamentally opaque and unequal, ways. As Graham (2005:564) stresses,

software sorting captures the crucial and often ignored role of code in directly, automatically and continuously allocating social or geographical access to all sorts of critical goods, services, life chances or mobility opportunities to certain social groups or geographical areas, often at the direct expense of others.

In addition to this first line of work, scholars have questioned the logics of self-referentiality conveyed by a number of applications (Pariser, 2011; Widmer, 2015). The starting point here is that software sorting - as we see it with the personalization of content on Facebook or Amazon but also in relation to a growing number of spatial media - works not only by profiling users via their digital history but also by connecting them to the digital activity of specific others: their social network and/or "calculated publics" (Gillespie, 2014), i.e. a group of other users identified through collaborative filtering methods as presenting similar purchase or frequentation behaviours as the user. Consequently, algorithms reproduce social aggregations that draw users with similar tastes and practices into "filter bubbles" (Pariser, 2011) in which they are confronted with content that corresponds to their pre-established interests and attitudes, thus reinforcing social polarization among like-minded people. This problematic also has crucial spatial implications in that it creates differing regimes of visibility of urban places for individuals and social groups, hence resulting in differing relations to both alterity and space (De Souza e Silva and Frith, 2012; Graham et al., 2013).

The two emerging key issues - software sorting and selfreferentiality - are, therefore, of fundamental importance if we are to understand and question how algorithms act in everyday life. Yet, the existing literature also presents a series of empirical and conceptual shortcomings beyond which we want to move.

First, by failing to provide truly empirical insights into how the agency of software is perceived, lived and possibly contested by people confronted by its actions, this literature has tended to reinforce the image of software as inherently powerful, coherent in its agency and unitary in its implications (Neyland, 2016; Ziewitz, 2016). Rather, in moving away from such an abstract stance on the agency of algorithms, we need accounts that consider "the ambivalence inherent in all technologies, the significant potential of contestation of, and resistance to, technology-supported forms of discrimination, and the deeply contingent nature of the process of appropriation of new technologies" (Coutard and Guy, 2007:713). By considering in empirical detail how "algorithms are lived with" (Beer, 2017:4) and imagined, gamed or contested by their users (Christin, 2017; Crawford, 2016), it is possible to balance pre-eminent narratives of the "powerful [algorithms] that rule, sort, govern, shape, or otherwise control our lives" (Ziewitz, 2016).

Second, it is also necessary to challenge the very conceptualizations and terminologies used for approaching the functioning and implications of algorithmic sorting and categorizing. As argued before, predominant narratives depicting algorithms as powerful entities that rule, sort and structure inequalities have implicitly referred to algorithms acting as a "law" (Lessig, 2006) that defines how we can live. Recently, however, different contributions have unsettled this representation of the functioning of algorithms and their effects as fixed, rigid and uniform (Kitchin, 2017:21; Klauser et al., 2014; Mackenzie, 2016; Ruppert, 2012). Cheney-Lippold ex- 
plicitly turns away from the metaphor of the law defining "static norms of conduct" (Cheney-Lippold, 2011:168), by showing that the algorithmic categorization of consumer audiences in online marketing practices does not draw clear lines between categories (e.g. man or woman) but works by constantly redefining the boundaries of such categories in a fluid way as new data are continually being added to the system. Similarly, Ruppert (2012) and Mackenzie (2016) emphasize how the modes of knowing subjects and populations through large datasets have become post-demographic (i.e. based on the activities, tastes and movements of people as captured by their ever-accumulating digital traces) instead of being based on predefined and relatively immutable socio-demographic categories. Such accounts have made apparent that the image of code as a stable architecture is not always suitable for understanding and questioning the actions performed by algorithms on everyday life. As a result, these engagements test alternative metaphors or conceptual frameworks to describe the fleeting realities at stake: "topology" (Ruppert, 2012), "monad" (Mackenzie, 2016), "soft biopower" (Cheney-Lippold, 2011), "modulation" (Ruppert, 2012) or Foucauldian "security" (Klauser et al., 2014). In this article, we propose the concept of foams as an additional lens through which to approach these realities.

\section{Ambiguities of algorithmic life}

This article builds on the two abovementioned moves away from the understandings of algorithms as inherently powerful and stable in their functioning and implications. Following the claim that the entanglements of algorithms with practice should be better considered, we propose to examine the lived side of "software-sorted geographies" (Graham, 2005) by way of an empirical study into the uses of the local search engine Foursquare. On this basis, drawing on the idea that these geographies are better understood as fluid and ephemeral realizations than as fixed and permanent enclosures, the article explores what it means to live in these fleeting realities. In other words, what this article aims to unveil is the possible ambiguities arising from a life in infinite modulations rather than in clear moulds - to use Deleuzian terminology (Deleuze, 1992:4).

Conceptually speaking, the article operationalizes Peter Sloterdijk's theory of spheres to investigate how Foursquare's algorithms shape the coexistential spatialities of the everyday. This further pursues the work of Evans (2015) who drew on Heidegger's and Sloterdijk's writings to study the uses of Foursquare as a location-based social network (LBSN). In his work, Evans already underlines how Foursquare, by connecting its user to others, allows a kind of "dwelling with" that can be interpreted through Sloterdijk's concept of spheres as shared spaces of perception and experience (Evans, 2015:75). If our own investigation builds on the one developed by Evans, it also differs from it in several important aspects. First, we focus on Foursquare's use as a personalized local search engine (and not as an LBSN), which we connect with literatures on software sorting, algorithmic personalization and the instabilities of algorithmic life. Second, we build more centrally on Sloterdijk's conceptualization of foam as an analytical lens that not only allows the technological production of inhabitable worlds to be described - a dimension already touched on by Evans - but also, and more fundamentally, permits the study of the unstable, fragile and ephemeral nature of these worldings. Foam, such is our basic assumption, enables us to address how coexistence unfolds in the fluidities and fragilities of contemporary algorithmic world creations. As such, it is particularly relevant for addressing not only the flexibility of algorithmic profiling and categorization but also the ambiguous relationalities of coexistence that unfold in these unstable and fleeting structures.

\section{Foursquare case study}

Our analysis draws on a case study, conducted between 2013 and 2014 in New York City. It focuses on the practices and perceptions of Explore, Foursquare's personalized local search engine, in use between 2011 and 2014 and forerunner of the current version of the app.

Launched in 2009, Foursquare primarily worked as a location-based game and social network relying on the creation of "check-ins" (location data) by users. From this first focus on gamification and social networking, the app's main purpose was successively redesigned, to develop a personalized local search engine, Explore, that would recommend places to go to in accordance with the user's history of location data, network of friends and similarity to other data producers or users. The functioning of Explore through combined logics of tracking and collaborative filtering still remains at the very core of the current so-called Foursquare City Guide app, which has, since 2014, become exclusively dedicated to local searching. This functioning is symptomatic of the profiling logics deployed for advertisement purposes in contemporary online consumer cultures and, as such, accounts for the study's exemplary value for understanding how these logics increasingly permeate everyday experiences of urban space. Furthermore, Foursquare is of immediate interest here in that it bears striking testimony not only to the intrinsic combination of the spatial and of the social as mentioned initially but also to the logics of subjectification that characterize today's "profiling machines" (Elmer, 2004).

The case study included 30 semi-structured interviews conducted with users of the app. New York City was chosen on the assumption that it would present an important base of users. New York is not only the city in which the app was created and popularized in the first place but also, given the volume and dynamism of the city's amenities, a context deemed 
to be particularly suitable for the use of local search engines. Following a first series of interviews with Foursquare users, we started different "snowballs" from these initial contacts. Given the plurality of services offered by Foursquare at the time of the fieldwork, interviewees were using the app for different purposes, amongst which resorting to the app as a local search engine featured most prominently. The semistructured interviews, therefore, allowed for the appreciation and study of the ways in which interviewees perceived and experienced the reception of tailored information and how they used, negotiated or contested it to make decisions about where to go.

\section{Sloterdijk's theory of spheres}

The work of the philosopher Peter Sloterdijk does not leave its readers indifferent. Whereas his magnum opus, Spheres, has started to be discussed across a wide range of academic fields, mirroring the oeuvre's exceptionally rich and multifaceted scope and ambition (Duclos, 2015; Elden et al., 2009; Schinkel and Noordegraaf-Eelens, 2011; Van Tuinen, 2007), it has also been criticized for displaying a problematic and reactionary world outlook (Sutherland, 2019) - a critique that echoes the larger malaise caused by the controversial stances expressed by the philosopher in his media appearances (see Meaney, 2018).

The logics of and reasons for Sloterdijk's controversial reception have started to be discussed elsewhere (Boos and Runkel, 2018; Korf, 2019) and would deserve more extensive analysis. This cannot be our ambition here. Our point is that Sloterdijk's theory of spheres - and his conception of foam more specifically - complement in interesting ways the abovementioned engagements with the software-sorted geographies of the present-day world. In what follows, we further detail this claim.

\subsection{Mediated co-inhabitation}

The first reason for our interest in Sloterdijk's theory of spheres lies in its overall conceptual perspective. In Spheres, Sloterdijk develops a relational and mediation-centred understanding of human beings as "being with something, in something" (Elden, 2011). Conceiving human existence as a matter of co-inhabitation, Sloterdijk approaches the question of "where we are, when we live" through the concept of "sphere", understood as socially created conglomerates of togetherness where human beings find protective refuge (Klauser, 2010:329). Spheres, therefore, are shared interior spaces in which humans find existential immunization from the outside world (Sloterdijk, 2011:28).

Importantly, however, Sloterdijk's main emphasis is not on these spaces as final products but on the processes and modes of mediation that shape these "vital spheric geometries" (Sloterdijk, 2011:11). Sloterdijk's Spheres offers a theory of mediation that seeks to explain how coexistence is rendered pos- sible and "where, when and in what medium it occurred" (Sloterdijk, 2016:267).

For our purposes, Sloterdijk's "philosophy of space/spatial philosophy" (Thrift, 2009:120), therefore, offers an overall relational and mediation-centred perspective for the study of how algorithms mediate spheres of coexistence and, connecting with the issue of immunization, of how people inhabit these shared spaces.

\subsection{Foam}

The second reason for our interest in Sloterdijk's Spheres relates to the concept of foam, which we here mobilize as an analytical tool for exploring the relationalities of algorithmic life. Overall, Sloterdijk uses three main spherical metaphors to explore differing relational logics of coinhabitation: (1) "bubbles", referring to the symbiotic relationships of intimate couplings; (2) "globes", expressing the macrospherical imaginaries of political and religious cosmologies; and (3) "foams", describing splintered spheres of togetherness in the contemporary post-holistic world. With the concept of foams, Sloterdijk aims to offer a "plural spherology", inspired - beyond holistic or contractual conceptions of society - by Tarde's monadology and his idea that "everything is a society" (Sloterdijk, 2016:274).

By approaching contemporary coexistence through the metaphor of foam as "multi-celled chaos [in which] constant leaps, redistributions and reformattings [occur]" (Sloterdijk, 2016:48), Sloterdijk provides a spherical interpretation of modern individualism as the outcome of a double process: the dismantling of society into self-centred egospheres on a microscale and the recombination of these entities, on a mesolevel, into wider, polynuclear, though fundamentally ephemeral, aggregations of togetherness.

It follows, first, that coexistence in foams is always to be understood as "co-isolation", referring to the ambiguous state of individuals who "can neither be truly united nor truly separate" (Sloterdijk, 2016:54) in their attempts to inhabit a type of sphericality characterized by self-withdrawal and momentary adjacency rather than by long-lasting solidarity. Second, with the foam metaphor, Sloterdijk also invites elaboration on the volatility, unreliability and, indeed, "liquidity" (Bauman, 2000) of contemporary world creations and conditions of coexistence.

In this type of vital spherical geometry, human immunity can no longer be envisaged as something gained through the devotion to something intimately enveloping or through participation in an all-encompassing whole. Rather, existential protection becomes an individual matter, "the individual contribution of an organism that actively sees to its separation from the environment" (Sloterdijk, 2016:182), marking a shift to civilization characterized by the collapse of old macro immune structures. The fragility and liquidity of the resulting sphericalities of life can be seen as a major deficiency, yet Sloterdijk also emphasizes that 
the suspended must be understood as a special kind of foundation, the hollow as a fullness in its own right, the fragile as the place and mode of the realest, and the unrepeatable as a higher phenomenon than the serial. (Sloterdijk, 2016:38)

In other words, foams are also fertile, allowing for local improvisations and creativity, and characterized by less deterministic and rigid forms of social affiliations.

In our analysis, we argue that Sloterdijk's depiction of foams as inherently fragile, momentary, yet also creative, spheres of co-isolation merits critical attention not only because of the power of software as a means of classification that connects and separates alike but also because of the inherent fragility and liquidity of the splintered self-containers and social conglomerates produced as a result. As we will show, this double problematic finds expression in a series of ambiguities that characterize the ways in which individuals relate to the spheres of coexistence that they attempt to inhabit on Foursquare.

It is on this level that Sloterdijk complements the existing literatures on the splintering logics of digital life - channelled through notions such as software sorting and algorithmic life. Yet, in turn, these literatures provide a wealth of insights into the exclusionary politics that run through and shape software sorting, a dimension largely unproblematized in Sloterdijk's account of coexistence in the "foam-cell society". Indeed, despite referring to splintered spheres of coexistence, the philosopher never problematizes these as indicators of wider social and political divisions and thus overlooks the power issues and exclusionary dynamics at work. Rather, foams are - quite controversially - contextualized in a world of "pampering", where hardship has disappeared and deficient beings are a "fiction" (Sloterdijk, 2016:651).

Thus, the two literatures must be brought together if we are to understand and empirically address the lived side of the splintering spheres of co-isolation that characterize contemporary algorithmic life. In what follows, this is what we do. Following Sloterdijk's bi-scalar understanding of foams, our analysis is structured into two main parts. First, we explore how Foursquare users live and perceive the egosphere mediated by the app, which is composed of self-referentially tailored spatial information (the isolated side of co-isolation). Second, we investigate how Foursquare users relate to the larger social conglomerates to which they are algorithmically connected (the connected side of co-isolation). Thus, it is by looking at the lived side of the mediated relationships to the self, to others and to space that we explore how life unfolds in these software-sorted geographies.

\section{Living the egosphere}

Foursquare implies tracking. The app deciphers each user's location to subsequently provide him or her with personalized recommendations. There is a logic of individuation at the core of Foursquare's functioning, centred on each user's ever-evolving behaviour and, therefore, data generation. The user's digital traces, then, lead to the production of an individual egosphere, that is, an environment offering personalized relations to places, depending on prerecorded preferences and subsequently identified regularities (types of places, kinds of food, price range, etc.). On this level, Foursquare works as a typical example of what Merrin (2014) describes as a "me-dia", that is, an informational device whose "streams and production [are] centred on the individual" (Evans, 2015:76).

Yet, as Gillespie puts it (Gillespie, 2014:173), the app "knows only what it is able to know". In our case, this is a sum of location data, whose patterns and regularities are used to understand "who" the user is. However, as much information remains untranslated in these data, the profiling always results in a partial version of reality and in the production of a fragmentary form of the subject and egosphere. In what follows, we study how the egospheres of Foursquare are lived and perceived by users. We do so by exploring two ideal types of user whose radically divergent experiences of the app underline a first series of ambiguities characterizing contemporary algorithmic life.

\subsection{The unintentional islander}

A number of interviewees did not consciously live the app as a me-dia, centred on their own practices and profiles. For these users, Foursquare was simply indicating the closest and/or the best-rated places around them. Although they identified different criteria, such as distance and ratings, to intervene in the ranking of the recommendations received, they were unaware of the tracking and subsequent personalization going on:

I am not sure [how places are ranked]... I am wondering if it's... I think it's by the ratings ... because it looks like it is based on the ratings. I have seen that the rating was higher, but the distance was further... so I don't think it is by the distance. (Lisa, 3 August 2013)

These users are unintentional "islanders" (Sloterdijk, 2016), sojourning in their self-referential environment without realizing it. If Foursquare's algorithmic egospheres are based on great efforts of design and technical production, the example at hand actually shows that for many, they are, in fact, characterized by a degree of automatization and opacity that makes it difficult to completely understand what is going on. This resonates with other literatures that have problematized the opacity with which algorithms govern everyday life (Graham, 2005; Klauser, 2017).

These users' unawareness of the app's egospherical functioning was further accentuated by their lack of curiosity about the app's relevance as a local search engine. Interested predominantly in the gaming and location-based social net- 
working dimensions of Foursquare - still central to the app at the time - these users consulted Explore but in passing and parallel, without acknowledging that the location data produced in their gaming or networking mindsets were influencing the recommendations obtained on Explore.

Interestingly, however, they were well aware of the visibility of their check-in data for other users, leading at times to more playful, if not strategically fake or fantasized, ways of producing and showing off their "locational self" to others. The digital histories of these interviewees, therefore, produced a somewhat blurry and erratic portrait of their actual locational practices:

When I first used Foursquare, I was afraid to check in to a place and maybe someone would find me there. And then I said, well, half of the time I like to play Foursquare as a check-in game to get the badges ... so if I just check in to a place that I am at, and then check in to four, five others... I get them confused. They don't know where I am at. (Camilla, 23 August 2013)

At first, I used to not want to check in to places that I thought were mundane, like I wouldn't check in to a coffee place or a laundry place [but only] if I was going somewhere that seemed interesting or exciting, I would post it. (Daniel, 18 April 2014)

This highlights a first ambiguity in the experience of Foursquare, in which ignorance on one level meets strategic instrumentalization on another, generating an imprecise datadriven egosphere that is largely incompatible with the official "script" (Akrich, 1992) intended by the app's developers, in which check-ins are meant to be reflective of the users' actual preferences and spatial practices. From a user perspective, this resulted in differing, and fundamentally fleeting, degrees and types of interest in the personalized environment created by the app, which remained highly abstract, albeit not completely devoid of critical attention, but, ultimately, misunderstood.

\subsection{Islanders by conviction}

Other interviewees expressed a very different attitude towards the app and its egospherical functioning. Often, these users had also initially used Foursquare as a gaming or social networking app. However, they had then started to resort to the app for more personal reasons, for lifelogging (i.e. as a personal archive of past locations) and, indeed, for accessing personalized spatial information on Explore. They often referred explicitly to the capacity of Foursquare to know and profile them: "Foursquare knows I love pizza, it knows I have a sweet tooth ... Like... this is all stuff that I like... [places] that I would go to!" (Gabriel, 5 September 2013) and "I trust Foursquare more [than Google Maps] because they have four years of check-in data from me... I feel that they know me a little bit better" (Ellen, $13 \mathrm{Au}-$ gust 2013). Interviewees of this second user type, such as Gabriel and Ellen, considered their data history to reflect a certain truth about their tastes, a truth that Explore was able to grasp and express in its recommendations. They used the app as a spatialized "ego technique" (Sloterdijk, 2016:544), allowing them to approach space through a "constant return" to themselves and to their past locational habits. The app, therefore, sustained the "auto-symbiosis" (Sloterdijk, 2016:547) of these users, who could reinforce their sense of self in these personalized environments. In this respect, algorithms also worked as "semantic antibodies or idea suppressors" (Sloterdijk, 2016:190) filtering the places that did not match the user's sense of self:

If you search on Google or something, the first thing that pops up, it's always a Starbucks Café because they are everywhere and they are popular. But because I don't go to Starbucks Café... I go to places like Gorilla Café; I go to small businesses cafés. If I go to a new town, [Foursquare] is going to find that small, you know, little coffee shop that is not a Starbucks... I don't want a map to show me all the Starbucks! I don't care where they are. (Adam, 5 August 2013)

Contrary to the first user type, these interviewees knew that their production of data affected the recommendations they would receive on Explore. As such, they were islanders by conviction, driven by self-centred motivations rather than by any interest in producing check-ins to interact with others in the game or LBSN. Adam (5 August 2013), for example, often mentioned that the more data he produced, the better his profiling would become. "I am mostly active on the app, checking in ... and that's mainly to make the Explore feature better... so yes, [my use of the app] is all kind of related to the Explore feature."

In his intention to "make the Explore feature better", Adam was posting check-ins to become more "algorithmically recognizable" (Gillespie, 2014:184). Not all interviewees were that strategic, but using the app for lifelogging generally made them more inclined to check in to places in a very conscious way, depending on what they thought reflected their actual locational selves. Yet, most of the time, interviewees still struggled to fully recognize themselves in Explore's outputs, which became particularly apparent when they were asked during the interview to launch the app and to comment on the recommendations received. In moving beyond an abstract description of the app, they admitted that their profiling was sometimes completely missing the point. Consider the example of Mark (5 September 2013):

The top three I've gone to frequently, and then I might look at this fourth one ... and so I might actually click on it and say, "what is this?"... But then like "Barclays centre" ... that kind of turns 
me off from the search 'cause that's a stadium! I am not going to go there to hang out on a Thursday night! ... those kinds of things turn me off from using Explore because it feels very much not... not tailored to me.

Thus, although these users valued the personalized service offered, they still perceived it as being far from coherent and fully relevant. Most of the time, this had come to be accepted as a normal aspect of the Explore experience. Users had internalized the fact that they could not take the recommendations at face value but needed to navigate through them carefully and refine them through repeated and gradually adapted searches, not forgetting to double-check other apps.

We find here another lived ambiguity of Foursquare, related to the tension between the promise of unicity and the standardization and mass production of this unicity. Indeed, Foursquare aims to provide each user with a unique service but does so through automated procedures and standard scripts that overlook the diversity of practices and motivations behind the recorded app uses. Connecting with Sloterdijk's (2016:530-531) account of the serial production of standardized isolation in contemporary housing units, the Foursquare example allows further elaboration on the tension between individuation and standardization from an algorithmic viewpoint, showing that the produced environments are lived in highly ambiguous ways, as things that are both prescriptive and, indeed, subject defining but also inherently limited. With this, we move towards the second broad level of our analysis, relating to the lived side of the mesostructures of contemporary algorithmic life, leading us further in the exploration of the Foursquare case study.

\section{Living the social foam}

Foursquare users are not only to be understood as islanders in informational self-containers derived from their previous digital history; they also take part in larger social ensembles in that their history is constantly connected to the activity of other data producers on the platform. These "others" can be all kinds of momentary and context-dependent alterities: a large group of users agreeing on the quality of a certain place; people having proved their "expertise" on the platform; or, as with the case of Foursquare Explore examined here, either users sharing similar spatial practices with the targeted user - what we have previously named, drawing on Gillespie (2014), "calculated publics" - or users defined as "friends".

In what follows, we claim that the combined processes of individuation and association produce yet another basic tension, the one that exists between the constant celebration of the self and the concomitant dependence on fluid affiliations to others. This argument is structured into two main parts, following the distinction between unknown others (calculated publics) and known others (friends). Together, the two parts shed light on the fluidity, ephemerality and fragility of the ensembles of togetherness mediated by Foursquare. Here, our analysis of the lived side of these ensembles focuses in particular on how our interviewees sought "their immunitary optimum" (Sloterdijk, 2016:500) in these relations and tried to dwell in these unstable and impermanent associations.

\subsection{Calculated publics - unknown others}

Gillespie (2014:188) proposes the notion of calculated publics to emphasize that digital media often invite us "to feel an affinity" with publics that are automatically produced for us by algorithms. This is what happens on Foursquare when users are recommended places to go that have been visited by other users who are calculated as being similar to themselves.

During the interviews, it was not easy to get our participants to talk about these calculated publics. Not all of them realized that behind the recommendation, "People who go to place $X$, also go to $Y$ ", their own check-ins were being crossreferenced with those of other users. When interviewees were aware of these calculations, their representations of these publics remained still rather limited. One of our interviewees referred to "people like me" (Neil, 14 August 2013) and another to "people who like this bar, which I've checked in to a lot" (Ellen, 13 August 2013), and, most of the time, the understanding of these publics consisted of explaining how collaborative filtering worked. It was difficult to generate discourses about these ensembles beyond the only thing that interviewees knew about them: they were composed of people presenting similar check-in habits to themselves. This inability to truly relate to calculated publics echoes the observation made by Crawford in referring to Amazon's book recommendations: "We are shown a calculated public, but we do not know its membership, its concerns, whether or why people loved or hated these books. There is simply a consensus: these books are frequently purchased together" (Crawford, 2016:80).

Dwelling in the relations to calculated publics was, therefore, not an easy task. Not only was it difficult to imagine who were the people comprising these publics and how many of them there were, but also it was difficult to really feel a sense of belonging to these ensembles. Interestingly, beyond the question of calculated publics, some of our interviewees referred to socio-demographic characteristics as factors of identification with other content producers on Foursquare. These quite conventional categories of identity were, therefore, still shaping our interviewees' imagination of what constituted "trustworthy others" on the app. Marina, for instance, did not use Explore because she considered the places and spatial practices of Chinese Americans (with whom she identified) to be underrepresented, whereas the fact that Gabriel imagined Foursquare users to be "young" was precisely a reason for him to trust the content displayed on the local search engine: 
If we are using Chinatown as an example... my favourite bakeries that are Chinese bakeries or run by Chinese immigrants are not that likely to be listed on Foursquare. And if I am not looking for that type of experience or place... that attracts the very Foursquare-heavy type of group, then... yeah... that's why I don't think I have actually gone to that many places purely out of a Foursquare recommendation. (Marina, 23 April 2013)

I feel like you have a better chance to get into something great with the app... because people our age are going to talk about it. (Gabriel, 5 September 2013)

In comparison to these rather classic and stable categories of identification, Explore's calculated publics were characterized by their fluidity and by the variable geometry of their membership. They not only were fluctuating according to the ever-evolving production of data by users but also were composed of different members depending on where the user was launching the app. If the fluidity and ephemerality of social foams seems relevant for tackling these fluctuating publics, our analysis of their lived side indicates that they were not a form of alterity that our interviewees particularly trusted.

\subsection{Friends - known others}

In comparison to these fluid publics, friends were an element of stability for our interviewees. Therefore, receiving recommendations for places visited by them was one of the main reasons they used and appreciated the app:

I care a lot about what my friends think. And also [following] these pages is helpful. Like Time Out New York, you know, something like that ... But ... yeah, the other one isn't that helpful for me. Like "people who like this also like this". It doesn't really ... connect for me. (Kim, $26 \mathrm{Au}-$ gust 2013)

Seeing that a place had been visited by their friends was, thus, a sign of confidence for most of our interviewees, who often declared that they chose a place on this basis. As raised by Evans, the concept of sphere as "a shared psycho-spatial immunological edifice" (Schinkel and Noordegraaf-Eelens, 2011:13) seems appropriate for describing the friends-mediated spatial experiences of our interviewees. Interestingly, however, the "shared edifice" was not based on the co-presence of users and their friends or aimed at fostering an interaction between them. The relation to friends on Explore was just serving the user's self-centred interest in finding a suitable place to go. Although many of our interviewees referred to the close relationships they had with some of their friends on the platform, it became clear that the existence of close ties was not imperative for the selfcentred objective pursued on the local search engine:

Once you see there is a shared interest... I feel like you have the history of what they like, you know what you like and you see a lot of commonalities, everything is matching up like... if I go visit somewhere that they have been to, I would say "hey, Jim and Maria were here, let's try that!" even though... I don't know if I've been in the same room ever as Jim and Maria... I just know we have a lot of shared interests and that allows me to kind of judge... I would totally trust their recommendations. (Mark, 5 September 2013)

Although the quite superficial bond described by Mark cannot be generalized to all friendship relations on the app, the "ensemble for cooperation" (Sloterdijk, 2016:567) he ephemerally forms with Jim and Maria is perfectly functional, because what matters is not the cultivation of social ties or a true understanding of who these people are but the possibility of recognizing oneself in their locational practices. In this case, relations to friends are somehow used to reinforce the user's own sense of self, thereby echoing Sloterdijk's (2016:56) observation that "however much [egospheres] might purport to be connected with other and outside things, they initially round themselves off purely in their respective selves."

Although it was easier to dwell in places recommended by friends rather than those endorsed by calculated publics, both alterities were characterized by a fundamental impermanence. Some parts of the city were, indeed, deprived of data produced by members of these ensembles and, therefore, impossible to approach by this route:
My neighbourhood [the Brooklyn Chinatown] is not as frequented ... it is off the beaten path ... and so when ... for instance, if I look up some place to go in my neighbourhood, the recommendations aren't as robust as they are here [in Manhattan]. There are still a lot of places that they suggest but they don't always have, you know, "ten of my friends have gone" to each one; and it's usu- ally "one person has gone here", "one person has left a tip there". But it's not as data rich be- cause... it's just a little bit more removed... so you know in that case you have to go by the tips of strangers ... which is not as personalized but it's still useful. (Ellen, 13 August 2013)

As suggested by Ellen, in data-poor parts of the city where she could not be connected to places endorsed by her friends, Foursquare's algorithms would indicate places frequented by "strangers", a sort of second-class alterity she nevertheless acknowledged as "useful". Again, this example underlines how users are flexibly connected to different social ensembles (friends, "people like me", strangers, etc.) depending on 
their location and on the availability of data produced by others. In this respect, the social geographies of Foursquare's recommendations are constantly evolving, not only temporally, with the continual production of data by users, but also spatially, as the user moves in the city and is flexibly reassigned to new social ensembles. On the lived side of these geographies, as expressed by Ellen, New York City was experienced as a patchy territory made up of data-rich areas easy to approach and personalize and of data-scarce ones, which remained more unfamiliar (Widmer, 2015).

In sum, this second part of our analysis also underlines a lived ambiguity of algorithmically produced social foams. This ambiguity was particularly apparent in the case of calculated publics, characterized by a paradoxical fluidity. On the one hand, these social foams were "fertile" and "creative" (to use Sloterdijk's own terms), in that they did not trap the user in rigid, deterministic and permanent moulds but continually adapted to his or her practices. On the other hand, these social ensembles were difficult to grasp, in their lack of a certain clarity, solidity and continuity. As a result, socio-demographic categories and relations to friends were met with less ambiguity and considered entities that were easier to relate to. Relations to friends were, however, also characterized by a spatial impermanence, experienced by our interviewees when they launched the app in parts of the city less frequented by this alterity.

\section{Conclusion}

Together, the two strands of analysis pursued above highlight how complex and ambiguous the experiences and relationalities are that characterize contemporary algorithmic life. Drawing on Peter Sloterdijk's theory of spheres, our account thus moves beyond existing literatures on the socio-spatial implications of software sorting that traditionally overestimate the unitary functioning and implications of governing through code. In contrast, we have made the case for the concept of foam offering a relevant conceptual framework for addressing the inherent fragility, ephemerality and liquidity of the forms of coexistence produced by socio-spatial media such as Foursquare. As shown empirically, the possibilities for existence and coexistence afforded by Foursquare are, in turn, lived and experienced in highly ambiguous ways.

By way of conclusion, it is worth revisiting below some of these lived ambiguities, with a view to developing a wider critique of the power dynamics inherent in contemporary algorithmic life that goes far beyond Sloterdijk's own writing on foam.

\section{Ambiguities of co-isolation}

Following Sloterdijk's bi-scalar account of the paradoxical state of co-isolation that characterizes togetherness in the foam society, our analysis approached the sphericalities produced by Foursquare on two levels as (1) splintering "ego- spheres", derived in a self-referential way from each user's ever-evolving generation of data, and (2) larger conglomerates, or "social foams", in which users are connected to differing alterities. Our study has emphasized the need to consider the state of co-isolation hereby created flexible and ephemeral, rather than composed of permanent moulds in which individuals are categorized and sorted along clear lines.

Having to deal with a "multi-celled chaos" (Sloterdijk, 2016:48) is a good way of summing up our interviewees' experiences of living in and with the spherical geometries of Foursquare. Indeed, although interviewees appreciated the services offered by the app, they also experienced it with some confusion, a certain amount of mistrust, and a sense of not being able to dwell confidently in the app's spheres of both tailor-made and cross-referenced recommendations without encountering difficulties. By pointing to the problems to find real clarity in the produced spheres of coexistence, our analysis has, therefore, underlined some of the ambiguities characterizing contemporary algorithmic life. Here, it is worth looking back at some specific and, indeed, symptomatic types of ambiguities highlighted in the preceding analysis.

A first ambiguity was that between unawareness and strategic instrumentalization or, put differently, between ignorance and appropriation. Although this ambiguity was particularly obvious in relation to those users we called unintentional islanders, it applied to all interviewees to some extent. To differing degrees, Foursquare users did not know exactly how the app worked, thereby highlighting the difficulties in elucidating the opacities of algorithmic life. Yet, in differing ways, users also appropriated the app for their own purposes; played with it employing more or less strategic means; and, in doing so, found their own ways of relating to it. This relation, however, remained inevitably limited, riddled with contradictions, and, thus, somewhat in between half-frustrating and half-irrelevant.

A second lived ambiguity of Foursquare resulted from the tension between the app's promise of unicity and the standardization and mass production of this unicity. The point here is that users are provided with their own personalized egosphere but these are produced in highly standardized ways, through predefined algorithmic rules of association and a uniform understanding of what the data generated by users stand for. People lived the resulting limitations of their own egosphere as such and never fully recognized themselves in their own profiling.

Third, this then produced a lived ambiguity between the constant celebration of the self and the concomitant dependence on differing affiliations to others. Social foams were, however, also experienced with ambiguity, particularly in the case of calculated publics. Although being affiliated to fluid, ever-changing and post-demographic publics allowed users to be categorized in less deterministic and permanent and, thus, more open and creative ways, they had trouble in relat- 
ing properly to these ephemeral social ensembles. More stable and clearer forms of affiliation (socio-demographic categories or friends) were considered more trustworthy and, therefore, were experienced with less ambiguity.

In the end, the unclear and unstable environments produced by Foursquare were lived with superficiality and remoteness. Indeed, users' experiences were characterized not only by ambiguities but also by a certain frivolity. Just as foams are light and brought to life through "anti-grave tendencies" (Sloterdijk, 2016:673), Foursquare's spheres of coisolation were experienced with frivolity regarding the exact functioning of the app, the tracking and profiling operated, the types of social relationships maintained through it, and the lack of relevance of some of the recommendations. The use of Foursquare was a world away from "the dogmatism of the serious, the weighty and the necessary" (Sloterdijk, 2016:647); it was “just" about finding places nearby, in quite short and furtive moments of consultation. The politics of algorithmic filtering and data collection were perceived to be remote and absent from such fleeting moments; these algorithmically sorted spheres of coexistence and their ambiguities were, after all, not real "matters".

Therefore, it is also in the very lightness and fluidity and, seemingly, anti-gravity of their functioning and experiences that algorithms exercise their power, which raises important further questions and issues and, indeed, points to another set of important paradoxes. Algorithmic procedures are powerful and deeply entwined in the everyday, but they are also evasive, light and remote; they are pervasive and omnipresent yet also diffuse and superficial and, thus, ultimately, very difficult to understand, to grasp and to question. They increasingly orchestrate everyday life, but the outcomes of this orchestration are not necessarily lived as clear, concrete or lasting. Therefore, not only is it difficult to take seriously what appear to be non-matters without adopting a certain amount of detachment or a degree of frivolity with regard to these issues, but also it is difficult to address such non-matters politically. As Cheney-Lippold put it, if we cannot clearly define or anticipate, nor indeed perceive or experience, the forms of social differentiation produced by algorithms or the ways in which specific categories such as race, gender, income, or age are re-enacted hereby, this means "we lack the vocabulary needed to enact a politics around [them]" and indeed lose the "expressive power" (Cheney-Lippold, 2017:62) to challenge and resist the politics of contemporary "life in media". After all, it is just foam...

Data availability. Due to privacy laws and to protect the identities of the interviewees, the interviews are not publicly accessible.

Author contributions. SW conducted the fieldwork from which the empirical insights are derived and wrote the original draft of the paper. The theoretical and analytical reflection of the paper was conducted jointly by the co-authors.

Competing interests. The authors declare that they have no conflict of interest.

Review statement. This paper was edited by Benedikt Korf and reviewed by two anonymous referees.

\section{References}

Akrich, M.: The description of technical objects, in: Shaping Technology/Building Society. Studies in Sociotechnical Change, edited by: Bijker, W. and Law, J., MIT Press, Cambridge, MA, 205-224, 1992.

Amoore, L. and Piotukh, V.: Algorithmic Life: Calculative Devices in the Age of Big Data, Routledge, London, 2015.

Bauman, Z.: Liquid Modernity, Polity Press, Cambridge, 2000.

Beer, D.: The social power of algorithms, Inform. Commun. Soc., 20, 1-13, https://doi.org/10.1080/1369118X.2016.1216147, 2017.

Blog Google: Now available: New ways to explore with Google Maps, Posted on 26 June 2018, available at: https://www.blog.google/products/maps/ now-avaible-new-ways-to-explore-google-maps/ (last access: 5 August 2019), 2018.

Blog Yelp: Introducing collections: Handpicked recommendations just for you, Posted on 24 May 2018, available at: https://blog.yelp.com/2018/05/ introducing-collections-handpicked-recommendations-just-for-you (last access: 5 August 2019), 2018.

Boos, T. and Runkel, S.: Einführung: Die ungeheuerliche Raumphilosophie von Peter Sloterdijk, Geogr. Helv., 73, 261272, https://doi.org/10.5194/gh-73-261-2018, 2018

Cheney-Lippold, J.: A new algorithmic identity: Soft biopolitics and the modulation of control, Theor. Cult. Soc., 28, 164-181, https://doi.org/10.1177/0263276411424420, 2011.

Cheney-Lippold, J.: We are Data. Algorithms and the Making of our Digital Selves, New York University Press, New York, 2017.

Christin, A.: Algorithms in practice: Comparing web journalism and criminal justice, Big Data Soc., 4, 391-409, https://doi.org/10.1177/2053951717718855, 2017.

Coutard, O. and Guy, S.: STS and the city: Politics and practices of hope, Sci. Technol. Hum. Val., 32, 713-734, https://doi.org/10.1177/0162243907303600, 2007.

Crampton, J.: Cartography: Maps 2.0, Prog. Hum. Geogr., 33, 91100, https://doi.org/10.1177/0309132508094074, 2009.

Crawford, K.: Can an algorithm be agonistic? Ten scenes from life in calculated publics, Sci. Technol. Hum. Val., 41, 77-92, https://doi.org/10.1177/0162243915589635, 2016.

Deleuze, G.: Postscript on the societies of control, October, 59, 3-7, 1992.

De Souza e Silva, A. and Frith, J.: Mobile Interfaces in Public Spaces: Locational Privacy, Control, and Urban Sociability, Routledge, New York, 2012. 
Duclos, V.: Le design du monde: De McLuhan à Sloterdijk, vers une anthropologie de l'espace en devenir, Working Paper, Fondation Maison des Sciences de 1'Homme, available at: https:// halshs.archives-ouvertes.fr/halshs-01167829/document (last access: 27 August 2020), 2015.

Elden, S.: Sloterdijk Now, Polity Press, Cambridge, 2011.

Elden, S., Mendieta, E., and Thrift, N.: Special issue: The worlds of Peter Sloterdijk, Environ. Plan. D, 27, 1-156, 2009.

Elmer, G.: Profiling Machines: Mapping the Personal Information Economy, MIT Press, Cambridge, MA, 2004.

Evans, L.: Locative Social Media: Place in the Digital Age, Palgrave Macmillan, Basingstoke, 2015.

Gillespie, T.: The relevance of algorithms, in: Media Technologies: Essays on Communication, Materiality, and Society, edited by: Gillespie, T., Boczkowski, P. J., and Foot, K. A., MIT Press, Cambridge, MA, 167-194, 2014.

Graham, M., Zook, M. and Boulton, A.: Augmented reality in urban places: Contested content and the duplicity of code, T. I. Brit. Geogr., 38, 464-479, https://doi.org/10.1111/j.14755661.2012.00539.x, 2013.

Graham, S.: Software-sorted geographies, Prog. Hum. Geogr., 29, 562-580, https://doi.org/10.1191/0309132505ph568oa, 2005.

Kitchin, R.: Thinking critically about and researching algorithms, Inform. Commun. Soc., 20, 14-29, https://doi.org/10.1080/1369118X.2016.1154087, 2017.

Kitchin, R. and Dodge, M.: Code/Space: Software and Everyday Life, MIT Press, Cambridge, 2011.

Klauser, F.: Splintering spheres of security: Peter Sloterdijk and the contemporary fortress city, Environ. Plan. D, 28, 326-340, https://doi.org/10.1068/d14608, 2010.

Klauser, F.: Surveillance \& Space, Sage, London, 2017.

Klauser, F., Paasche, T. and Söderström, O.: Michel Foucault and the smart city: Power dynamics inherent in contemporary governing through code, Environ. Plan. D, 32, 869-885, https://doi.org/10.1068/d13041p, 2014.

Korf, B.: Schwierigkeiten mit der kritischen Geographie, Geogr. Helv., 74, 193-204, https://doi.org/10.5194/gh-74-193-2019, 2019.

Lessig, L.: Code: Version 2.0, Basic Books, New York, 2006.

Lyon, D.: Surveillance as Social Sorting: Privacy, Risk, and Digital Discrimination, Routledge, New York, 2005.

Mackenzie, A.: Distributive numbers: a post-demographic perspective on probability, in: Modes of Knowing, edited by: Law, J. and Ruppert, E., Mattering Press, Manchester, 115-135, 2016.

Meaney, T.: A celebrity philosopher explains the populist insurgency. The New Yorker, 26 February 2018, available at: https://www.newyorker.com/magazine/2018/02/26/ a-celebrity-philosopher-explains-the-populist-insurgency (last access: 5 August 2019), 2018.
Merrin, W.: The rise of the gadget and hyperludic media, Cult. Polit., 10, 1-20, https://doi.org/10.1215/17432197-2397209, 2014.

Murakami Wood, D. and Graham, S.: Permeable boundaries in the software-sorted society: Surveillance and differentiations of mobility, in: Mobile Technologies of the City, edited by: Sheller, M. and Urry, J., Routledge, London, 177-191, 2006.

Neyland, D.: Bearing account-able witness to the ethical algorithmic system, Sci. Technol. Hum. Val., 41, 50-76, https://doi.org/10.1177/0162243915598056, 2016.

Pariser, E.: The Filter Bubble: What the Internet Is Hiding from You, Penguin Press, New York, 2011.

Ruppert, E.: The governmental topologies of database devices, Theor. Cult. Soc., 29, 116-136, https://doi.org/10.1177/0263276412439428, 2012.

Schinkel, W. and Noordegraaf-Eelens, L.: In Media Res: Peter Sloterdijk Spherological Poetics of Being, Amsterdam University Press, Amsterdam, 2011

Sloterdijk, P.: Bubbles: Spheres Volume I: Microspherology, Semiotext(e), Los Angeles, 2011.

Sloterdijk, P.: Globes: Spheres Volume II: Macrospherology, Semiotext(e), Los Angeles, 2014.

Sloterdijk, P.: Foams: Spheres Volume III: Plural Spherology, Semiotext(e), Los Angeles, 2016.

Sutherland, T.: Peter Sloterdijk and the 'security architecture of existence': Immunity, autochthony and ontological nativism, Theor. Cult. Soc., 7, 193-214, https://doi.org/10.1177/0263276419839119, 2019.

Thrift, N.: Different atmospheres: Of Sloterdijk, China, and site, Environ. Plan. D, 27, 119-138, https://doi.org/10.1068/d6808, 2009.

Thrift, N. and French, S.: The automatic production of space, T. I. Brit. Geogr., 27, 309-335, https://doi.org/10.1111/14755661.00057, 2002.

Van Tuinen, S.: Critique beyond resentment: An introduction to Peter Sloterdijk's jovial modernity, Cult. Polit., 3, 275-306, 2007.

Widmer, S.: Experiencing a personalised augmented reality: Users of Foursquare in urban space, in: Algorithmic Life: Calculative Devices in the Age of Big Data, edited by: Amoore, L. and Piotukh, V., Routledge, London, 2015.

Wilken, R. and Goggin, G.: Locative media - definitions, histories, theories, in: Locative Media, edited by: Goggin, G. and Wilken, R., Routledge, London, 1-19, 2015.

Ziewitz, M.: Governing Algorithms: Myth, Mess, and Methods, Sci. Technol. Hum. Val., 41, 3-16, https://doi.org/10.1177/0162243915608948, 2016. 